\title{
Induction and Catabolite Repression of Chondroitinase in Batch and Chemostat Cultures of Proteus vulgaris
}

\author{
By C. F. THURSTON \\ Department of Microbiology, Queen Elizabeth College, London W. 8
}

(Received 23 July 1973)

\begin{abstract}
SUMMARY
Chondroitinase was induced in Proteus vulgaris by chondroitin sulphate or by $N$-acetylgalactosamine. With batch cultures growing on chondroitin sulphate or $\mathrm{N}$-acetylgalactosamine the differential rate of chondroitinase synthesis increased throughout the exponential growth phase. Induction of chondroitinase by chondroitin sulphate was prevented by glucose, glycerol, lactate, pyruvate or succinate. The rate of uptake of chondroitin sulphate by Proteus vulgaris suspensions was not altered by the presence of glucose. With steady state chemostat cultures, limited either by the supply of chondroitin sulphate or nicotinic acid, the specific activity of chondroitinase was maximal at diffusion coefficient $(D)=0 \cdot \mathrm{I} 8 \mathrm{~h}^{-1}$. Addition of glucose to nicotinic acid-limited chemostat cultures resulted in an exponential reduction in chondroitinase specific activity; this could be partially prevented by the simultaneous addition of 5 mm-adenosine cyclic- $3^{\prime}, 5^{\prime}$-monophosphate.
\end{abstract}

\section{INTRODUCTION}

Several studies have shown that Proteus vulgaris has the ability to depolymerize chondroitin sulphates. Dodgson \& Lloyd (1957) reported that degradation of the polymer preceded the removal of sulphate groups from the molecule, and Martinez, Wolfe \& Nakada (I959) showed that the growth of Proteus vulgaris on yeast extract was stimulated by the inclusion of chondroitin sulphate in the medium, consistent with this compound being used as a carbon source.

Subsequently Yamagata, Saito, Habuchi \& Suzuki (1968) purified and characterized the chondroitin sulphate-degrading enzyme extracted from Proteus vulgaris NCTC 4636, grown on nutrient broth supplemented with $\mathrm{O} \cdot \mathrm{I} \%$ chondroitin sulphate $\mathrm{C}$. Chondroitinase (chondroitin sulphate A, B, C-lyase, EC. 4.2.-.-.) was shown to degrade chondroitin sulphate A, chondroitin sulphate $\mathrm{C}$ and dermatan sulphate (chondroitin sulphate $\mathrm{B}$ ) by an elimination reaction yielding 4,5-unsaturated sulphated disaccharides as sole products. When either chondroitin sulphate $A$ or dermatan sulphate was used as substrate the product was $\Delta \mathrm{Di}-4 \mathrm{~S}$, [2-acetamido-2-deoxy-3- $O$ - $(\beta$-D-gluco-4-enepyranosyluronic acid)-4- $O$-sulpho-D-galactose]. With chondroitin sulphate $\mathrm{C}$ as substrate the product was $\Delta \mathrm{Di}-6 \mathrm{~S}$, [2-acetamido-2-deoxy3-O-( $\beta$-D-gluco-4-enepyranosyluronic acid)-6- $O$-sulpho-D-galactose]. Yamagata et al. (I968) further showed that Proteus vulgaris contained two specific sulphatases for which $\Delta \mathrm{Di}-4 \mathrm{~S}$ and $\Delta \mathrm{Di}-6 \mathrm{~S}$ were substrates. The product in both cases being $\Delta \mathrm{Di}$-oS [2-acetamido2-deoxy-3-O-( $\beta$-D-gluco-4-enepyranosyluronic acid)-D-galactose]. Further metabolism of $\Delta$ Di-oS has not been elucidated.

The work described in this paper is concerned with the control of the synthesis of chondroitinase by Proteus vulgaris, which has remained little understood despite the intensive study of the catalytic properties of the enzyme referred to above and the increasing use of the 
purified enzyme as an analytical and preparative reagent in the study of cartilage glycosaminoglycans (Mayes \& Hansen, 1965; Hascall, Riolo, Hayward \& Reynolds, 1972; Kempson, Muir, Pollard \& Tuke, 1973).

\section{METHODS}

Organism and media. Proteus vulgaris NCTC 4636 was maintained on nutrient agar slopes. All growth media except nutrient broth were based on a minimal salts medium (MM) which contained $(\mathrm{g} / \mathrm{l}): \mathrm{K}_{2} \mathrm{HPO}_{4}, \mathrm{I}_{4} \cdot 0 ; \mathrm{KH}_{2} \mathrm{PO}_{4}, 6 \cdot 0 ; \mathrm{NH}_{4} \mathrm{Cl}, 2 \cdot 0 ; \mathrm{MgSO}_{4} \cdot 7 \mathrm{H}_{2} \mathrm{O}, 0.2$; iron as Fe-EDTA complex, $0 \cdot 0002$. When chondroitin sulphate $\mathrm{C}$ or Casamino acids were added they were introduced before autoclaving to give a final concentration of $2.0 \mathrm{~g} / 1$. For batch cultures, nicotinic acid was added as a filter-sterilized solution to give a final concentration of $0.5 \mathrm{mg} / \mathrm{l}$. Media for chemostat experiments were: $M M+2.0 \mathrm{~g} / \mathrm{l}$ chondroitin sulphate $+0.5 \mathrm{mg} / \mathrm{l}$ nicotinic acid (chondroitin sulphate limited); or $\mathrm{MM}+2 \cdot 0 \mathrm{~g} / \mathrm{l}$ chondroitin sulphate $+20 \mu \mathrm{g} / \mathrm{l}$ nicotinic acid (nitotinic acid limited). Other additions to media are described in the legends to Tables and Figures.

Growth. All cultures were grown at $37^{\circ} \mathrm{C}$ and $\mathrm{pH} 7 \cdot 0$. Biomass was determined turbidometrically using an EEL colorimeter with a blue filter (OBIO). Extinction was linearly related to dry weight of bacteria over the range of culture densities studied. For single determinations of chondroitinase activity and to provide inocula, $20 \mathrm{ml}$ cultures in $250 \mathrm{ml}$ conical flasks with sidearms were incubated on an orbital shaker. Batch cultures (I l) were incubated in a 21 glass vessel, aerated at $500 \mathrm{ml} / \mathrm{min}$ and stirred mechanically with a stainless steel impeller and a stationary stainless steel baffle. Chemostat cultures $(80 \mathrm{ml})$ were aerated at $80 \mathrm{ml} / \mathrm{min}$ and stirred magnetically. Fresh medium supply was controlled by an LKB Varioperspex pump (LKB Instruments, London). The culture volume was maintained constant by means of a steeply angled sidearm overflow tube. Samples from steady states were collected after not less than four culture volumes had been pumped through the system under fixed conditions. For experiments where the effect of additions to the chemostat was monitored, samples were collected from the overflow into tubes packed in ice. In assembling the data, each sample was assumed to have the properties of an instantaneous sample taken at a time halfway through the collection period.

Preparation of cell-free extracts. Samples of culture were centrifuged at $4{ }^{\circ} \mathrm{C}$ and all subsequent operations were carried out at o to $4{ }^{\circ} \mathrm{C}$. Organisms were washed and resuspended in 0.05 M-tris-acetate $(\mathrm{pH} \mathrm{8.0)}$ and disrupted by five $30 \mathrm{~s}$ periods of treatment in a $100 \mathrm{~W}$ ultrasonic disintegrator tuned for maximum power output. Supernatant extracts were recovered after the broken-cell suspensions had been centrifuged at $35000 \mathrm{~g}$ for $\mathrm{I} h$, and were stored frozen without measurable loss of chondroitinase activity.

Protein determination. Protein was determined using the method of Lowry, Rosebrough, Farr \& Randall (195I). Bovine serum albumin standards were used, containing the same concentration of tris-acetate buffer as the unknown samples.

Chondroitinase assay. Based on information given by Mayes \& Hansen (1965) and Yamagata et al. (I968), a continuous spectrophotometric assay was developed. In a final volume of I $\mathrm{ml}$, the assay mixture contained $500 \mu \mathrm{g}$ chondroitin sulphate $\mathrm{A}, 50 \mu \mathrm{mol}$ tris-acetate

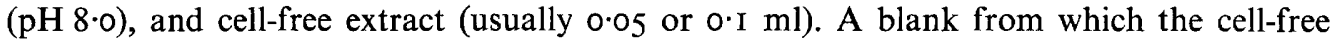
extract was omitted was used. The assay was carried out in silica cuvettes with $\mathrm{I} \mathrm{cm}$ pathlength, using an SP800B double beam recording spectrophotometer (Unicam Instruments Ltd, Cambridge), with a water-jacketed cuvette holder maintained at $37^{\circ} \mathrm{C}$ by water pumped from a thermostated bath. Cell-free extract was added after the other components of the 


\section{Table I. Effect of carbon source on chondroitinase activity} with chondroitin sulphate as inducer

\section{Carbon source}

Chondroitin sulphate

Chondroitin sulphate + Casamino acids

Chondroitin sulphate + nutrient broth

Nutrient broth

Chondroitin sulphate + glucose

Chondroitin sulphate + glycerol

Chondroitin sulphate + sodium lactate

Chondroitin sulphate + sodium pyruvate

Chondroitin sulphate + sodium succinate
Chondroitinase

(E.U./mg protein)

$$
\begin{aligned}
& 1.70 \\
& 1.70 \\
& 1.70 \\
& \sim 0.04 \\
&< 0.01 \\
&< 0.01 \\
&< 0.01 \\
&< 0.01 \\
&< 0.01
\end{aligned}
$$

Batch cultures were sampled at the end of exponential growth. General conditions of culture, medium composition and assay procedure are described in Methods. Glucose, glycerol, and the sodium salts of lactic, pyruvic and succinic acids were $10 \mathrm{~g} / \mathrm{l}$.

assay mixture had been allowed to equilibrate to $37^{\circ} \mathrm{C}$, and increase in extinction at $232 \mathrm{~nm}$ was measured. The initial rate of increase of extinction was used to calculate the rate of formation of $\Delta \mathrm{Di}-4 \mathrm{~S}$, given that the molar extinction coefficient $(\epsilon)$ for this compound is $5 . \mathrm{I} \times \mathrm{IO}^{3}$ litre. $\mathrm{mol}^{-1} . \mathrm{cm}^{-1}$ at $232 \mathrm{~nm}$ (Yamagata et al. 1968). One enzyme unit (E.U.) catalysed the production from chondroitin sulphate $A$ of $\mathrm{r} \mu \mathrm{mol}$ of $\Delta \mathrm{Di}-4 \mathrm{~S} / \mathrm{min}$ at $37^{\circ} \mathrm{C}$. All extracts were assayed in duplicate.

Chemicals. $N$-acetyl-D-galactosamine, $N$-acetyl-D-glucosamine and adenosine- $3^{\prime}, 5^{\prime}$-cyclic, monophosphoric acid (cyclic-AMP) were obtained from Sigma (London) Chemical Co. Ltd, Kingston-upon-Thames, Surrey. Vitamin-free Casamino acids were obtained from Difco Laboratories, East Molesey, Surrey. Nicotinic acid was from Griffin \& George Ltd, Wembley, Middlesex. Chondroitin sulphate C (extracted from shark cartilage) was from Koch-Light Laboratories, Colnbrook, Buckinghamshire. Highly purified chondroitin sulphate A was provided by Dr Helen Muir, Department of Biochemistry, Kennedy Institute of Rheumatology, London W. 6.

\section{RESULTS}

\section{Effect of medium composition on chondroitinase specific activity}

Proteus vulgaris grew on chondroitin sulphate $\mathrm{C}$ as sole source of carbon (other than its required vitamin). High chondroitinase specific activity was detected in extracts from organisms grown in this way (Table I). Similar high specific activities were evident when organisms had been grown in nutrient broth or Casamino acids supplemented with chondroitin sulphate $\mathrm{C}$, whereas growth on nutrient broth alone gave chondroitinase specific activity which was only 2 to $3 \%$ of the value obtained when chondroitin sulphate $\mathrm{C}$ was present (Table I). In contrast, chondroitinase was not detectable in extracts from cultures grown on minimal medium containing chondroitin sulphate $\mathrm{C}$ together with either glucose, glycerol, lactate, pyruvate or succinate (Table 1), nor was diauxic growth observed.

Table 2 shows chondroitinase specific activities from organisms grown in media which did not contain chondroitin sulphate. $N$-acetylgalactosamine induced chondroitinase synthesis, giving a maximum specific activity which was two-thirds of the maximum obtained in batch cultures with chondroitin sulphate $\mathrm{C}$ as inducer. No other compound tested invoked a measurable increase of enzyme activity. 
Table 2. Chondroitinase activity in the absence of chondroitin sulphate

Carbon source*

[Chondroitin sulphate]

$N$-acetylgalactosamine

Galactosamine $\dagger$

Galactose

$\mathrm{N}$-acetylglucosamine

Glucuronic acid $\dagger$

None
Chondroitinase

(E.U./mg protein)

$$
\begin{array}{r}
{[I \cdot 70]} \\
I \cdot 17 \\
0.02 \\
<0.01 \\
<0.01 \\
0.02 \\
0.02
\end{array}
$$

Batch cultures were sampled at the end of exponential growth. The basic medium was $\mathrm{MM}+2 \mathrm{~g}$ Casamino acids/l. The additions named in the Table were added after autoclaving as filter-sterilized solutions to give a final concentration of $2 \mathrm{~g} / \mathrm{l}$.

* In addition to Casamino acids.

$\dagger$ Galactosamine and glucuronic acid did not increase final biomass above the level found with Casamino acids alone. These compounds may not have been taken up by the cells.

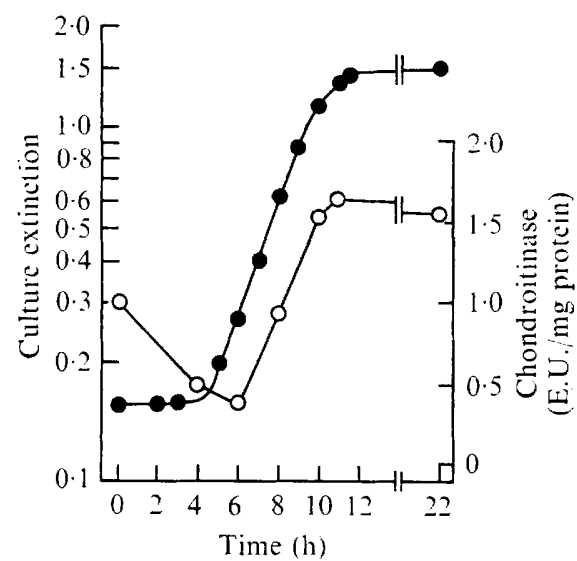

Fig. I

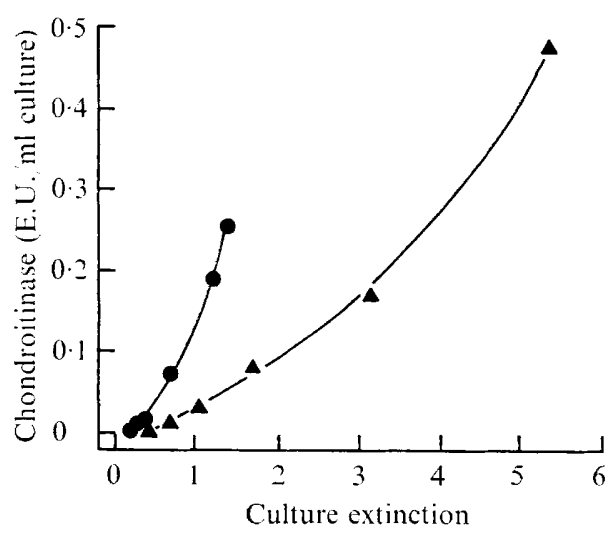

Fig. 2

Fig. I. Growth and chondroitinase activity of a Proteus vulgaris batch culture grown on MM+ chondroitin sulphate. The inoculum culture was grown on $\mathbf{M M}+$ chondroitin sulphate + Casamino acids. Treatment of samples, measurement of culture density (O) and enzyme specific activity (O) are described in Methods.

Fig. 2. Differential rate of chondroitinase synthesis was determined during exponential growth on $\mathrm{MM}+$ chondroitin sulphate $(\boldsymbol{O})$, and $\mathrm{MM}+N$-acetylgalactosamine $(2 \mathrm{~g} / \mathrm{l})+$ Casamino acids $(\boldsymbol{\Delta})$. E.U./ml of culture was calculated assuming uniform cell disruption by ultrasonic treatment, which was corroborated by comparison of protein released with extinction for each sample.

\section{Kinetics of chondroitinase induction in batch cultures}

Chondroitinase specific activity increased progressively during growth of Proteus vulgaris in media containing either chondroitin sulphate $\mathrm{C}$ (Fig. I) or $\mathrm{N}$-acetylgalactosamine (results not shown). The differential rate of enzyme synthesis also increased progressively during growth with either inducer as shown in Fig. 2. Chondroitinase specific activity did not increase after exponential growth had ceased. 


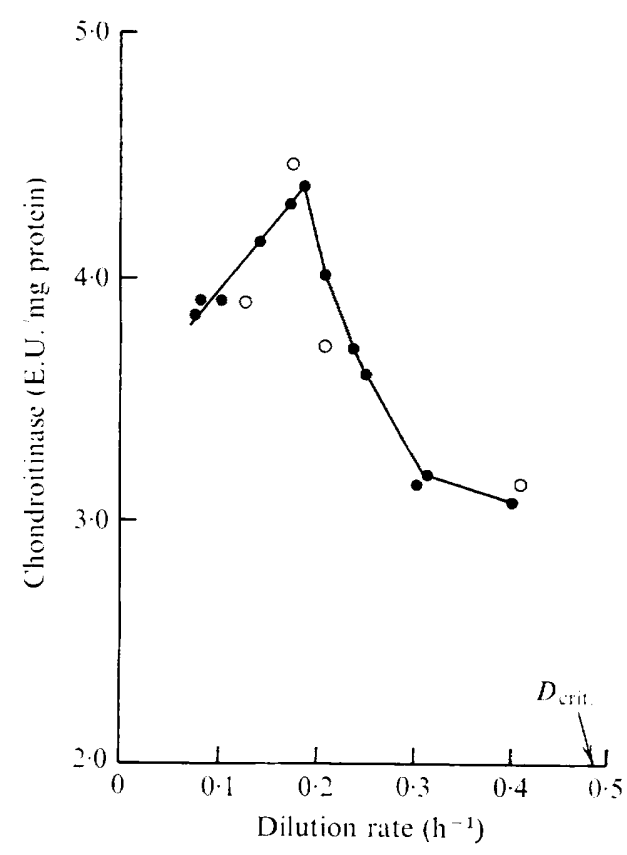

Fig. 3

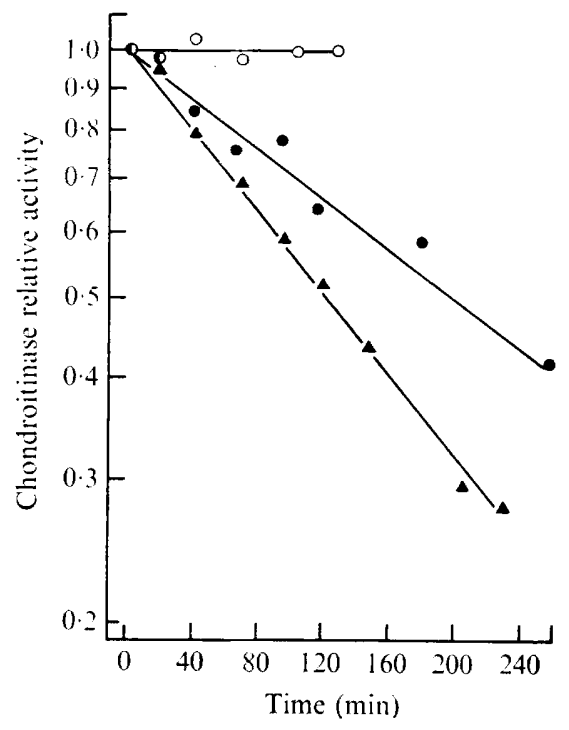

Fig.4

Fig. 3. Chondroitinase specific activity as a function of dilution rate in chemostat cultures. The mean of determinations on four samples are shown for each dilution rate tested, where two samples were taken from each of two steady states set up on different occasions. The limiting nutrient was $2 \mathrm{~g}$ chondroitin sulphate/l $(0)$, or $20 \mu \mathrm{g}$ nicotinic acid/l $(\mathrm{O})$.

Fig. 4. Catabolite repression of chondroitinase in chemostat cultures. Nicotinic acid-limited cultures in steady state were used at $D=0.3 \mathrm{~h}^{-1}$, giving a generation time of $139 \mathrm{~min}$. Sampling procedure is described in Methods. Chondroitinase activity is expressed as a proportion of the specific activity of zero-time samples, which was 3.0 E.U./mg protein. At zero time glucose was added simultaneously to the chemostat vessel and the medium reservoir to give a concentration of $5.0 \mathrm{~g} / \mathrm{l}$. Cyclic-AMP was added in the same way to give a final concentration of $5 \mathrm{~mm}$. Additions: Glucose, $(\boldsymbol{\Delta})$; glucose + cyclic-AMP, (O); cyclic-AMP, (O).

\section{Chondroitinase activities of Proteus growing under steady state conditions}

Samples were withdrawn from chemostat cultures growing at fixed dilution rates between 0.08 and $0.42 \mathrm{~h}^{-1}\left(D_{\text {erit }}=0.48 \mathrm{~h}^{-1}\right)$. Chondroitin sulphate was the growth-limiting nutrient in one series of experiments, and nicotinic acid in a second. With both types of nutrient limitation, chondroitinase specific activity increased with dilution rate up to $D=0 \cdot 18 \mathrm{~h}^{-1}$ and then decreased as the dilution rate was increased further (Fig. 3). Maximum specific activity was 4.4 E.U./mg protein. All extracts from steady state cultures showed higher chondroitinase specific activities than those from batch cultures.

\section{The effect of glucose and cyclic-AMP on chondroitinase activity in chemostat cultures}

When glucose was added to nicotinic acid-limited chemostat cultures, chondroitinase specific activity declined exponentially (Fig. 4) whilst biomass density remained unchanged. With a chemostat operating at $D=0.30 \mathrm{~h}^{-1}$, the culture doubling time is $2 \cdot 3 \mathrm{~h}$. Hence it could be concluded that glucose completely prevented chondroitinase synthesis since the 
Table 3. Chondroitinase assay with whole cells as a measure of chondroitin sulphate uptake

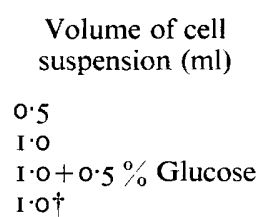

Apparent chondroitinase activity*

$\left(\Delta \mathrm{E}_{23 \mathrm{~g}} / \mathrm{min}\right)$

0.024

0.039

0.042

0.300

A cell suspension grown in $\mathrm{MM}+$ chondroitin sulphate + Casamino acids was washed and resuspended in 0.05 M-tris-acetate $(\mathrm{pH} 8.0)$ at a cell density of $0.5 \mathrm{mg} / \mathrm{ml}$ (dry wt). This was included in an assay system which had a total volume of $3.0 \mathrm{ml}$, containing $5.0 \mathrm{mg}$ chondroitin sulphate A. The sonicated cell sample was not cleared by centrifugation as in the procedure described in Methods for preparation of cell-free extracts. Otherwise the procedure resembles that described for chondroitinase assay in cell-free extract.

* Average of duplicates.

+ Cells sonicated prior to assay.

specific activity of chondroitinase also diminished by one-half in $2 \cdot 3 \mathrm{~h}$. Five mM-cyclic-AMP added with the glucose lowered the rate at which chondroitinase activity declined, whilst in the absence of glucose addition of cyclic-AMP had no effect on the steady state enzyme level (Fig. 4).

\section{Influence of glucose on the rate of chondroitin sulphate uptake by} Proteus vulgaris

Chondroitin sulphate was degraded by chondroitinase in suspensions of whole organisms (Table 3). If the organisms were broken by ultrasonic treatment, the rate of degradation increased eightfold. Hence it appeared that the rate of uptake of chondroitin sulphate was the rate-limiting step in its degradation by whole cells. As glucose did not lower the apparent chondroitinase activity of whole cells it was concluded that glucose did not interfere with uptake of chondroitin sulphate. This conclusion would not be valid if the difference between the activity measured with broken and whole cells resulted from rapid metabolism of the product of the reaction catalysed by chondroitinase in the whole-cell preparation. Whilst such an explanation was not excluded by experiment, it is unlikely to occur in non-growing cells.

\section{DISCUSSION}

The specific activity of chondroitinase in Proteus vulgaris was similar in batch cultures grown either with chondroitin sulphate as sole source of carbon or with mixtures of chondroitin sulphate and Casamino acids (Table I). It is inferred therefore that Casamino acids are a 'neutral' carbon source with respect to regulation of chondroitinase synthesis, and that the chondroitinase activity in cultures with Casamino acids as sole source of carbon can be taken to represent a basal level of synthesis (0.02 E.U./mg protein; Table 2$)$. In batch cultures, chondroitin sulphate evoked a maximum 85 -fold increase in chondroitinase activity from the basal level and in chemostat cultures, a maximum 220-fold increase. Although it is metabolized by Proteus, $\mathrm{N}$-acetylgalactosamine is, in a sense, a gratuitous inducer, since metabolism does not involve the reaction catalysed by chondroitinase.

In Escherichia coli, induction of $\beta$-galactosidase by lactose is an indirect effect as lactose is converted by $\beta$-galactosidase to allolactose which is the true inducing metabolite (Jobe \& 
Bourgeois, 1972). Induction of chondroitinase during growth on chondroitin sulphate may be a similar indirect effect, where the true inducing metabolite is a product of chondroitinase activity rather than its substrate. Although the pathway of chondroitin sulphate catabolism is not fully understood, $\mathrm{N}$-acetylgalactosamine is a likely intermediate (Yamagata et al. 1968). Our results do not demonstrate that $N$-acetylgalactosamine is the inducer during growth on chondroitin sulphate, but it is a possibility. It is made less likely by the observation that the maximum specific activity of chondroitinase during growth with $\mathrm{N}$-acetylgalactosamine in the medium is not as high as the maximum observed when Proteus is grown with chondroitin sulphate (Table 2). Alternatively, this could result from a relatively low rate of uptake of $N$-acetylgalactosamine by the organisms. The immediate products of the reaction catalysed by chondroitinase, $\Delta \mathrm{Di}-4 \mathrm{~S}$ or $\Delta \mathrm{Di}-6 \mathrm{~S}$, could also be inducers as could their nonsulphated product $\Delta \mathrm{Di}$-oS. These possibilities have not been experimentally tested. Chondroitinase induction appears nevertheless to be highly specific as no induction was observed with galactose or $\mathrm{N}$-acetylglucosamine, whilst the action of galactosamine remains uncertain as the results do not establish that it was taken up by Proteus vulgaris (Table 2). When the organism was grown on nutrient broth, chondroitinase activity detected was variable, but significantly above the basal level, which indicated a weak induction by some (unknown) component of this medium (Table $\mathbf{I}$ ).

Chondroitinase synthesis was severely repressed by a wide range of compounds such that in batch cultures the specific activity was lowered below the basal level (Tables I and 2) and also below the minimum detectable in the assay (0.0I E.U./mg protein). This effect was confirmed for glucose in chemostat culture (Fig. 4). Glucose repressed chondroitinase synthesis (in cultures that had been induced by chondroitin sulphate) to a level that was immeasurably low, eliminating the possibility of distinguishing transient and permanent effects. Glucose repression was only partially relieved by 5 mM-cyclic-AMP (Fig. 4). This concentration is sufficient completely to reverse the effect of glucose on $\beta$-galactosidase and serine deaminase synthesis in Escherichia coli (McFall \& Bloom, 1971) and on $\beta$-galactosidase synthesis in Proteus inconstans Plac ${ }^{+}$(De Crombrugghe, Perlman, Varmus \& Pastan, I969).

The relationship between the cellular content of chondroitinase and dilution rate in steady state cultures (Fig. 3) is comparable to that established for a number of other inducible enzymes which are also subject to catabolite repression (Clarke, Houldsworth \& Lilly, 1968; Dean, 1972). In contrast, the inability to establish a stable differential rate of enzyme synthesis in exponential batch cultures is unusual and cannot presently be explained, whilst it is noteworthy that both chondroitin sulphate and $\mathrm{N}$-acetylgalactosamine induced chondroitinase synthesis in the same way (Fig. 2).

I thank Dr Helen Muir for generously supplying purified chondroitin sulphate A, and Elizabeth Cook for her capable technical assistance.

\section{REFERENCES}

Clarke, P. H., Houldsworth, M. A. \& Lilly, M. D. (i968). Catabolite repression and the induction of amidase synthesis by Pseudomonas aeruginosa 8602 in continuous culture. Journal of General Microbiology 5I, 225-234.

De Crombrugghe, B., Perlman, R. L., Varmus, H. E. \& Pastan, I. (1969). Regulation of inducible enzyme synthesis in Escherichia coli by cyclic-3' $5^{\prime}$-adenosine monophosphate. Journal of Biological Chemistry 244, $5828-5833$. 
DEAN, A. C. R. (1972). Influence of environment on the control of enzyme synthesis. Journal of Applied Chemistry and Biotechnology 22, 245-259.

Dodgson, K. S. \& LLoYd, A. G. (I957). Study on sulphatases. XVIII. Preparation of chondroitinase-free chondrosulphatase from extracts of Proteus vulgaris. Biochemical Journal 66, 532-539.

Hascall, V. C., Riolo, R. Z., HAYwaRd, J. \& ReYNolds, C. C. (1972). Treatment of bovine nasal cartilage proteoglycan with chondroitinases from Flavobacterium heparinum and Proteus vulgaris. Journal of Biological Chemistry 247, 4521-4528.

JoBE, A. \& BourgeoIs, S. (1972). lac Repressor-operator interaction. VI. The natural inducer of the lac operon. Journal of Molecular Biology 69, 397-408.

Kempson, G. E., Muir, H., Pollard, C. \& Tuke, M. (1973). The tensile properties of the cartilage of human femoral condyles related to the content of collagen and glycosaminoglycans. Biochimica et biophysica acta 297, 456-472.

Lowry, O. H., Rosebrough, N. J., Farr, A. L. \& Randall, R. J. (195I). Protein measurement with the Folin phenol reagent. Journal of Biological Chemistry 193, 265-275.

Martinez, R. J., Wolfe, J. B. \& NaKada, H. I. (1959). Degradation of chondroitin sulphate by Proteus vulgaris. Journal of Bacteriology 78, $217-224$.

MAYES, J. S. \& HANSEN, R. G. (1965). An enzymatic method for the determination of chondroitin sulphates. Analytical Biochemistry 10, 15-22.

MCFALL, E. \& BLOOM, F. (1971). Catabolite repression in the D-serine deaminase system of Escherichia coli $\mathrm{K}-\mathrm{I} 2$. Journal of Bacteriology 105, $24 \mathrm{I}-248$.

Yamagata, T., Saito, H., Habuchi, O. \& SuzUis, S. (1968). Purification and properties of bacterial chondroitinases and chondrosulphatases. Journal of Biological Chemistry 243, I 523-I 535. 